IZA DP No. 5433

Time-Bound Opportunity Costs of Informal Care:

Consequences for Access to Professional Care, Caregiver Support, and Labour Supply Estimates

Wolter H.J. Hassink

Bernard van den Berg

January 2011 


\title{
Time-Bound Opportunity Costs of Informal Care: Consequences for Access to Professional Care, Caregiver Support, and Labour Supply Estimates
}

\author{
Wolter H.J. Hassink \\ Utrecht University \\ and IZA \\ Bernard van den Berg \\ University of York
}

\author{
Discussion Paper No. 5433 \\ January 2011
}

IZA

P.O. Box 7240

53072 Bonn

Germany

Phone: +49-228-3894-0

Fax: +49-228-3894-180

E-mail: iza@iza.org

Any opinions expressed here are those of the author(s) and not those of IZA. Research published in this series may include views on policy, but the institute itself takes no institutional policy positions.

The Institute for the Study of Labor (IZA) in Bonn is a local and virtual international research center and a place of communication between science, politics and business. IZA is an independent nonprofit organization supported by Deutsche Post Foundation. The center is associated with the University of Bonn and offers a stimulating research environment through its international network, workshops and conferences, data service, project support, research visits and doctoral program. IZA engages in (i) original and internationally competitive research in all fields of labor economics, (ii) development of policy concepts, and (iii) dissemination of research results and concepts to the interested public.

IZA Discussion Papers often represent preliminary work and are circulated to encourage discussion. Citation of such a paper should account for its provisional character. A revised version may be available directly from the author. 
IZA Discussion Paper No. 5433

January 2011

\begin{abstract}
Time-Bound Opportunity Costs of Informal Care: Consequences for Access to Professional Care, Caregiver Support, and Labour Supply Estimates
\end{abstract}

Patterns of informal care are documented throughout the day with Dutch time use diary data. The diary data enable us to identify a, so far overlooked, source of opportunity costs of informal care, i.e. the necessity to perform particular tasks of informal care at specific moments of the day. Some care tasks are relatively unshiftable, while other tasks are shiftable implying that they can be performed at other moments of the day or even on different days. In particular, household and organization activities seem to be shiftable for employed caregivers, while personal care seems to contain unshiftable activities. This implies an additional opportunity cost of providing personal care tasks. As the care recipient's need for care may be related to the possibility to shift informal care throughout the day, we conclude that one should be careful with using care need as an instrument of informal care in labour supply equations.

JEL Classification: J2, I3

Keywords: $\quad$ use of time, joint production, informal care, paid work, opportunity cost, labor supply

Corresponding author:

Wolter Hassink

Utrecht School of Economics

Utrecht University

Janskerkhof 12

3512 BL Utrecht

The Netherlands

E-mail:w.h.j.hassink@uu.nl 


\section{Introduction}

Informal care is crucial for long-term home care. As a result of the care demands of the care recipient, this can be defined as a quasi-market composite commodity consisting of heterogeneous parts produced (paid or unpaid) by one or more members of the social environment of the care recipient (Van den Berg et al., 2004). A major part of long-term home care is informally provided by family or friends of the care recipient. This also seems to hold true if care recipients receive a cash benefit, also denoted as a personal care budget, to purchase long-term home care including informal care (Van den Berg and Hassink, 2008). Therefore, informal caregivers sometimes receive payment for (part of) the care they provide, as being paid is included in the definition of informal care.

In the medical and social sciences literature, caregivers have reported negative effects on their physical and mental health, finances, social life and leisure as well as labor market participation (Pearlin et al., 1990; Kramer, 1997; Hughes et al., 1999; Schulz and Beach, 1999; Dunn and Strain, 2001; Savage and Bailey, 2004; Hirst, 2005; and Yamazaki et al., 2005)). Providing informal care might involve extra expenditures (Van den Berg et al., 2004) and informal caregivers with paid jobs may possibly have lower wages compared with similar non-caregivers (Heitmueller and Inglis, 2007) or work less hours or are less likely to participate on the labour market (Ettner, 1996; Heitmueller, 2007). Another potential (and substantial) source of caregivers' opportunity costs are possible health losses for the informal caregivers due to caregiving (Schulz \& Beach, 1999). Although caregiving can impose a considerable burden on caregivers, they also report satisfaction with providing care, see e.g. Jacobi et al. (2003), Andrén and Elmståhl (2005) and Zapart et al. (2006). Obviously, availability of professional care might influence the effects reported. Using instrumental variables, Van Houtven and Norton (2004) and Bolin et al. (2007) focus on the substitution between informal care and professional care utilization.

A potential drawback of the literature described is that it is mainly based on survey data. Typically, in surveys a few questions retrospectively ask how much time people spend on providing informal care during e.g. the previous week. Time use diaries might provide more valid estimations of time spent on informal caregiving compared with survey data (Van den Berg and Spauwen, 2006). On top of that, diaries provide more detailed information about patterns of (informal caregivers) time use throughout the day. However, collecting diary information is costly and puts a burden on respondents, which might be a serious drawback in caregiving research as caregivers already experience the burden of providing informal care. This might be an explanation of the lack of detailed information about patterns of providing 
informal care throughout the day or between days in the available literature. To the best of our knowledge, there is no empirical evidence of variation in caregivers' patterns of time use throughout the day, for instance, associated with paid work or biological activities such as sleeping.

This paper extends to the previous literature by describing patterns of informal care throughout the day. Despite the ample evidence that informal care and paid work are substitutes (Ettner, 1996; Carmichael and Charles, 1998 and 2003; Heitmueller, 2007), there is no specific information about shifts of time spent on informal care during the day which can be associated with changes in specific patterns of paid work. Average informal care may be different between both groups, as opportunity costs of providing informal care might be higher for caregivers with paid work (Ettner, 1996; Heitmueller, 2007). While these studies compared the daily levels of informal care, we consider the fluctuations of informal care throughout the day. These fluctuations are driven by daily rhythms of care - for instance at mealtimes and when going to bed - which need to be provided at particular times of the day. These time-bound care tasks are related to the type of care instead of the intensity of care.

In this paper, we distinguish between shiftable and non-shiftable types of informal care. Some caregiving responsibilities may be shiftable over the day or even between days, while other tasks might be non-shiftable by nature if it is necessary to be provided at specific moments of the day. In economic terms, in addition to the opportunity costs due to the number of care hours, there may be opportunity costs that originate from non-shiftable tasks. These time-bound opportunity costs have two implications. First, the trade-off between informal care and (hours of) paid work depends on the type of informal care, which is not necessarily related to the number of hours of care. Second, the supply of professional home care including support programs for informal caregivers should not only relate to the amount of informal care provided but also to the nature of the informal care provided. Professional home care could have a positive external effect in terms of labour market participation of informal caregivers if it substitutes the non-shiftable types of informal care. The supply of respite care-programs could be tailored to the care tasks provided. To avoid non-participation in respite care-programs due to the non-shiftable nature of specific care tasks, it is even more important to acknowledge the difference between shiftable and non-shiftable informal care tasks. 


\section{Timing of informal care}

Various types of informal care can be distinguished, which includes household activities, instrumental activities of daily living, activities of daily living, surveillance and in some countries even medical related tasks (McDaid, 2001; Wimo et al., 2002; Riewpaiboon et al., 2009). In order to come up with an aggregated measure of informal care, it is quite common in empirical applications to add up the number of hours of various tasks of informal care that are provided. However, it might mask the mentioned heterogeneity of informal care provision throughout the day. Some activities need to be given at specific moments of the day on a daily base, e.g. in the morning, afternoon, and evening. This seems to be especially true for getting ready or dressing. Other activities could easily be skipped or spread out through the day or week, for instance household activities such as cleaning the house, shopping or organizational tasks such as administration.

From an economic perspective, the actual hours of care depend on the care needed by the care recipient and the opportunity costs incurred by the (potential) caregiver(s) (Van den Berg et al., 2005). The terms care need and demand are used interchangeable throughout this paper acknowledging the differences between both concepts in the health economics literature. Need is a proxy for the potential to benefit from health care utilization whereas demand relates to preferences and ability to pay (Hurley, 2000). Care need is usually measured along multiple dimensions (e.g. physical and mental health etc.). An important source of informal caregivers' opportunity costs is the monetary value of forgone time as a result of the care provided to the care recipient, often measured using a variable indicating the aggregate number of hours of informal care provided (Van den Berg et al., 2006). Another potential (and substantial) source of caregivers' opportunity costs is possible health loss for the informal caregivers due to caregiving (Schulz \& Beach, 1999).

We will introduce a new source of opportunity costs that is hitherto overlooked in the literature. This extra source of opportunity costs might arise if specific care tasks are not shiftable. As mentioned before, for specific types of care need, there may be unshiftable tasks. Hence, it is likely that, to a certain extent, personal care may be related to specific moments of the day so that they are unshiftable. In sum, this new source of opportunity costs is relevant as long as informal care is not perfectly shiftable over the day or between days.

On some occasions, the caregiver may reduce opportunity costs in terms of forgone time by combining informal care with other activities. One of the specific features of informal care is that it can be provided simultaneously with other non-market activities: so-called joint production (Juster \& Stafford, 1991). Obviously, certain types of tasks are more easily 
combined compared to others. For instance, a caregiver can easily shop for the care recipient and his/her own household at the same time. In contrast, it seems much harder to combine informal care and paid work in general because in most employment relationships employees have to show up at the work floor. On some occasions they could provide informal care during paid work time (such as arranging appointments with health care providers), but these kinds of tasks are just exceptions to the rule. A crucial implication of having to show up at the work floor is that an employed caregiver might shift provision of informal care to the period in which she has no paid work obligations. In general terms: as long as informal care is perfectly shiftable over the day or between days joint production might partly reduce opportunity costs of informal care.

To calculate the opportunity costs of informal care in terms of time forgone, most studies start with a one-dimensional time measure, which is the number of hours spent on informal care (Carmichael \& Charles, 2003) or a dichotomous measure of informal care, for instance more or less than 20 hours per week (Heitmueller, 2007). In formal terminology, the caregiver's labour supply is modelled as follows:

$$
H=\beta_{1} C+\beta_{2}{ }^{\prime} X+u
$$

where $H$ is the number of hours of paid work; $C$ is the number of hours of informal care; $X$ is a vector of control variables, which for instance includes wages; and $u$ is an error term, which contains all the variables which are not captured by $C$ and $X$. As long as there is no correlation between $u$ and both $C$ and $X$, Ordinary Least Squares (OLS) provides consistent estimates of the coefficients $\beta_{1}$ and $\beta_{2}$. In econometric terms, this error term correlates with neither $C$ nor $X$. In epidemiologic terminology, in the linear regression model, the variables in $u$ are not confounding variables because they correlate only with $H$ and not with $C$ or $X$.

A major issue in the literature of health economics is that a causal effect of $C$ on $H$ is crucial for developing health policy, but $C$ cannot be treated as exogenous in equation (1). Ideally we would like to exploit a natural experiment, but obviously one cannot easily experiment with randomly attributing people to intervention and control groups in order to measure the impact of $C$ on $H$. A consequence of an endogenous $C$ is that the error term $u$ also includes factors associated with the caregiver's opportunity costs that jointly affect the caregiver's decisions about $C$ and $H$. Consequently, OLS does not yield a causal effect from $C$ on $H$. Therefore, to solve this problem, economists propose to instrument the endogenous $C$ 
by so-called instrumental variables. A valid instrumental variable must meet two criteria. First, an instrumental variable needs to be relevant, so that it is strongly correlated with $C$. Second, an instrumental variable needs to be exogenous, so that it is uncorrelated with $u$.

A few studies have used the care recipient's care need as an instrumental variable (Ettner, 1997; Bolin et al., 2008; Heitmueller, 2007). Their main argument is that care need obviously is correlated with hours of provided informal care, but that it not directly correlates with labour supply. Obviously, care need is measured in various ways. In the case of parental caregiving, both Ettner (1997) and Bolin et al. (2008) use a standard self-assessed health measure with five answering categories. In both papers, the children assessed their parent's health by using this scale. Heitmueller (2007) does not restrict his analysis to parental caregiving and uses a measure of care need focussing on work limitations due to health issues. In addition, some studies applied instrumental variables that are related to the composition of the household. Ettner (1997) used the number of brothers and sisters, parental age, parental health, parental marital status, and parental socio-economic status as additional instruments; Bolin et al. (2008) applied parent's health status, age, the number of respondent's brothers and sisters and the distance towards the residence of the parents; Heitmueller (2007) used the additional instruments homeownership, the number of sick and disabled people in the household, age of the parents and the geographical proximity of parents and friends.

Consistent with equation (1), all studies mentioned considered the number of hours of caregiving to measure the intensity of informal care. We argue that a second dimension of time should be incorporated. This dimension should also include the necessity to provide informal care on a daily basis or at specific moments in the day. In the latter case, caregivers incur additional opportunity costs as result of the timing of informal care. Thus, the labour supply equation becomes:

$$
H=\beta_{1} C+\beta_{2}^{\prime} X+\beta_{3} C T+v
$$

Where $C T$ is a measure of the intensity of time-bound informal care, which results from tasks that are unshiftable throughout the day. Hence, $C T$ reflects the necessity to time informal care. The parameter $\beta_{3}$ has a negative sign, since paid work will be lower for larger opportunity costs of bound time-bound informal care. $v$ is an error term. So far, studies have not controlled for measures of $C T$ in the labour supply equation, so that $C T$ will be part of the error term $u$ in equation (1). If the omitted $C T$ is positively correlated with $C$, it can be shown 
that for equation (1) the OLS-estimator is inconsistent and that it renders an overestimate of the true parameter $\beta_{1}$.

We will investigate the importance of the intensity of time-bound informal care on the number of hours of work in equation (2). Consequently, it is informative whether the error term $u$ in equation (1) contains $C T$. Time-bound informal care will be measured by the patterns of informal care throughout the day. We will start with caregivers who do not have any paid work activities at all. Timing may be different for different activities. Our testing criterion is that timing is not important if there is no difference in the daily patterns of informal care between employed caregivers and caregivers without any paid job. To be more precise, we will create a counterfactual, by exploiting information from observing all caregivers for two days. For the employed persons, we consider patterns of informal care on days that they do not have paid work (ceteris paribus on the calendar day), so that we may compare them with the other group of caregivers who have no paid work at all.

If $C T$ is part of the error term $u$ in equation (1), we may reconsider the validity of the two criteria with respect to the instrumental variable care need in equation (1). First, care need is strongly correlated with number of hours of informal care, $C$. This still may be true, for all three of our categories of informal care. Second, it is assumed that care need is uncorrelated with $u$ and hence it must be uncorrelated with $C T$. This is not true for all categories of informal care. In particular, time bound opportunity costs are large for unshiftable tasks, such as personal care. On many occasions, unshiftable tasks may be related to care recipients with a higher care need.

Hence, as long as informal care only consists of shiftable tasks, there is nothing wrong with using the care recipient's care need as an instrument for the number of hours of informal care. On the other hand, if informal care also includes unshiftable routines, such as personal care, the instrumental variable may be invalid, since it may be correlated with the error term of equation (1). In other words, if there are time-bound opportunity costs of informal care, instrumental variables methods that are based on the care recipient's need of care will deliver biased parameter estimates of the effect of $C$ on $H$.

\section{Data}

The data were collected in April of 2002. We inquired 568 persons from the population of caregivers who participated in earlier research and who had indicated that they were willing to participate in future research. These persons were part of a broader sample of 3,258 informal 
caregivers who were sampled with the help of 40 (out of 59) approached Dutch regional support centres for informal caregivers between October and December 2001. See Van den Berg et al. (2005) for more details. Approaching caregivers via support centres implies that the sample consists of persons who provided a lot of care, as they had asked the centres for support. 301 caregivers (53\%) returned a time use diary and a survey about their sociodemographic characteristics. In order to get a representative picture of the informal care without making too heavy a demand on the respondents, we asked them to report their time use for two specific days (randomly assigned by us) or two backup days. Additional selection criteria were that the day of response is known (276 respondents) and that each respondent provided diary information for two days. It resulted in a selected sample of 199 persons who reported their use of time on 398 days for 38,137 time periods (quarters of an hour). Due to missing information on time use, 71 time periods were excluded from our analyses. Furthermore, for a smaller selection of 189 persons (378 days and 36,216 quarters of an hour), we used information on three different types of informal care, which will be discussed below in further detail.

$<$ Table 1 about here >

The respondents reported their use of time for 21 different calendar days. 69 respondents (138 days) had a paid job. They had paid work obligations on 78 days $(7,478$ quarters of an hour), while on the remaining 60 days (5,750 quarters of an hour) there were no activities of paid work at all. For caregivers without a paid job, the activities were registered on 260 days (25,005 quarters of an hour).

Table 1 reports the main characteristics of the respondents. The average age is 56.6; 29 percent of the caregivers are male; they have had 13.7 years of education; 84 percent are married; their average monthly household income is 1747 Euros; 66 percent live together with the patient; the average age of the patient is 59.7; 52 percent of the care recipients are male. Table 1 also reports the averages for the caregivers with paid work (second column) and without paid work (third column) as well as the p-values of a two-sample t-test (with equal variances). There are some differences between both groups of caregivers. Employed caregivers tend to be somewhat younger (49.5 versus 60.4) and higher educated (14.4 versus 13.4); on average they tend to have a higher income (1990 Euros versus 1618 Euros); less often live together with care recipient (53 percent versus 72 percent); they tend to have to care for a male care recipient less often (45 percent versus 56 percent).

For each quarter of an hour, the diary registered specific time use for one or more (simultaneous) activities. These activities are leisure, biological activities (sleep and personal 
care), informal care, paid work, and household activities. Three types of informal care were distinguished: Activities of Daily Living (ADL), Instrumental Activities of Daily Living (IADL), and Household activities of Daily Living (HDL). Also see Davis et al. (1997) and Van den Berg et al. (2006).

With respect to the definitions of each of the three types of informal care, the respondents were carefully instructed. First, ADL includes: Support with personal care such as dressing, hair combing and shaving; eating, drinking and taking medication; moving around inside and outside the house (including visiting health care suppliers); visiting the toilet; supervision. Second, IADL includes: Support with financial matters or other organizational tasks; visiting family and friends or journeys; social support. Third, HDL includes: Housecleaning; preparation of foods and drinks; washing, ironing or sewing; shopping; chores, gardening, maintenance; looking after children. An important feature of the diary is that informal caregivers could distinguish HDL informal care from household activities for themselves by ticking a different column for the same activity: informal care versus own activities or both (Van den Berg and Spauwen, 2006). In what follows, we will refer to the three types of informal care as personal care (ADL), organizational activities (IADL), and household activities (HDL).

The three types of informal care may reflect different time-bound opportunity costs. Some of the care tasks may be shiftable throughout the day, whereas other tasks need to be done on a daily base at specific moments of the day. This seems to be especially true for personal care. The household activities could be easily be skipped or spread out through the day or the week. The organization of daily living does not seem to be day specific.

$<$ Table 2 about here $>$

Table 2 shows the averages of specific activities of time use for different groups of caregivers. The first column is for all caregivers. The averages are: informal care (34.1 percent), paid work (5.0 percent), biological activities (39.4 percent), leisure (22.0 percent), and household activities (19.6 percent). These percentages add up to $120.1 \%$ because of joint production, so that for about 20 percent of the time the activities are done simultaneously. Informal caregivers with and without a paid job provided similar amounts of informal care, while only caregivers without a paid job spent more time on doing more organizational tasks.

\section{Method}

We will describe the estimation method that is used to determine the patterns of use of time throughout the day. Since we wanted to correct the patterns of activity for calendar day we 
applied a regression model. No caregiver-specific control variables (e.g. age and gender of the caregiver) are needed when assuming strict exogeneity and independence between the explanatory variables and the individual-specific error term (Wooldridge, 2002).

For each of the four activities (sleep, leisure, informal care, and paid work) the empirical model is

$$
I_{i t}=\sum_{t=2}^{96} \delta_{t} Q_{t}+\sum_{d=2}^{17} \gamma_{d} D_{d}+\varepsilon_{i t}
$$

The dependent variable $I$ is a $0-1$ indicator variable for the specific activity within the quarter of the day. Subscript $i$ refers to the i-th caregiver. Subscript $t$ registers the quarter of the day, for which $t=1$ corresponds to 0:00 a.m. $-0: 15$ a.m. $Q$ is a 0-1 indicator variable for quarter of the day. The parameter $\delta_{t}$ (times 100) registers the percentage point difference in activity at $t$ relative to $t=1$. We controlled for the influence of the calendar day $d$, by including a set of $0-1$ indicators $D_{d} \cdot \varepsilon$ is a random error term.

Equation (3) is estimated as a Linear Probability Model. The empirical analysis reports graphically the development of 100 times $\hat{\delta}_{t}(t=2, \ldots, 96)$ throughout the day for each of the activities.

$<$ Figure 1 about here $>$

\section{Results}

\section{Differences between the activities}

We take the development of informal care, household activities, leisure, and paid work during the day into consideration. See Figure 1, which reads as the percentage points difference of the use of time relative to 0:00 a.m. - 0:15 a.m. E.g., the probability of care at 8:00 a.m. is about 20 percentage points higher compared to the reference period. Figure 1 indicates that informal care is of equal importance between 9:00 a.m. and 9:00 p.m.; for household activities there is a mode at 12:00 p.m. and 6:00 p.m.; leisure peaks in the evening, while paid work is done relatively more in the morning.

\section{Composition of informal care}

Are there any differences in terms of number of hours of informal care, for which we distinguish personal care, organizational activities, and household activities? We consider 
differences between caregivers who have no paid work at all and the counterfactual group of employed caregivers at days on which they do not have paid work activities. Any difference implies that it may be necessary to further distinguish informal care to the different activities of informal care in equation (1).

Table 2 shows that the level of informal care is higher for the caregivers without a paid job (39.4 percent) than for the employed caregivers (20.3 percent at days of paid work; 28.6 percent at days without paid work activities). However, when we consider the three activities of informal care, the patterns become different. The amount of time spent is only slightly lower for household activities (10.0 versus 11.3 percent) and personal care (9.5 versus 12.6 percent); both differences are statistically significant at the 1-percent level. On the other hand, for informal care for organizational purposes, the differences are substantially higher for caregivers without a paid job (25.8 versus 16.5 percent, which is statistically different). We conclude it may be important to further distinguish informal care with respect to the organizational activities in equation (1).

$<$ Table 3 and Figure 2 about here $>$

\section{Simultaneity of informal care}

Are there any differences in terms of simultaneity between informal care and other activities? Possible differences would imply that the employed caregivers could reduce their opportunity costs by having more simultaneous activities. Table 3 considers the simultaneity between informal care and other activities. Apparently, there is no simultaneity with paid work. Furthermore, unemployed caregivers are more likely to have simultaneous activities (24.5 percent), while employed caregivers have a higher simultaneity (14.6 percent) on days they do not work. This is because a paid job is less easy to combine with other activities. For all activities, simultaneity is higher for unemployed caregivers. There is even simultaneity with biological activities (5.9 percent versus 2.6 percent) likely because biological activities include personal care but also because providing informal care might include supervising the care recipient.

The terms in brackets show the correlation between informal care and the other activities. There are negative associations with paid work (-0.12), biological activities $(-0.38)$, and leisure (-0.06), whereas for household activities the correlation is positive (0.21). All of the correlation coefficients are statistically different from zero at the 1-percent level. 
Figure 2 portrays the patterns of simultaneity throughout the day for all caregivers. E.g. the chance of simultaneous informal care with household activities at 6:00 p.m. is about 30 percentage points higher compared to 0:00 a.m. - 0:15 a.m. It appears that there are two peaks of care and household activities: at 12:00 a.m. and at 6:00 p.m. Simultaneity of informal care with leisure and paid work is of minor importance. A comparison of Figure 1 and Figure 2 shows that the patterns are similar for household activities.

There are two explanations for the simultaneity of household activities and informal care. First, the caregiver is able to reduce the opportunity costs of informal care by timing household activities with informal care. Second, caregivers may have little choice but to combine activities. Perhaps caregiving includes a leisure activity, which in other circumstances might not be preferred by the caregiver; or perhaps caregivers have to combine activities because there are only so many hours available to fit in all the tasks that have to be tackled. Those who must be in constant attendance, for example, might watch television alongside the care recipient and do their own ironing at the same time. Yet, they may feel completely constrained by their caring role.

$<$ Figures 3 - 5 about here $>$

\section{Patterns of informal care}

What are the differences in terms of the daily patterns of informal care? If there are any differences, then the timing of care has an effect on a number of hours in equation (2). We consider the patterns of informal care throughout the day for the different types of informal care (Figures 3 - 5). In particular, we are interested in whether there are differences in the fluctuations of informal care throughout the day between caregivers without paid work and the counterfactual observations.

The first type of informal care is care in terms of household activities. Figure 3 shows two modes for the unemployed caregivers. The first peak is in the morning between 9:00 a.m. and 1:00 pm. The second peak is around 6:00 p.m. E.g., the likelihood of informal care in terms of household activities is about 25 percentage points higher at 6:00 p.m. (relative to 0:00 a.m. - 0:15 a.m.). On days without paid work, the pattern of the employed caregivers mimics the first pattern very well. Again, there were two peaks at the same time interval. On the other hand, on days of paid work, there is only a peak at 6:00 p.m. Hence, at days of paid work, there are no additional activities before or after work. Instead, there is a continuation of the normal routines. 
Figure 4 concentrates on organization. For caregivers without paid work, the type of care gradually increases throughout the day from 8:00 a.m. to its peak between 8:00 p.m. and 9:00 p.m. (at which the likelihood of providing informal care in terms of organization is more than 30 percentage points higher (compared to 0:00 a.m. - 0:15 a.m.). For employed caregivers, we observe two modes. The first peak is at 4:00 p.m. and the second peak is between 8:00 p.m. and 9:00 p.m. On days on which employed caregivers do not have any paid work, on average informal care is equal to that of the other group of caregivers. It even seems as if there is more informal care from caregivers in the afternoons of their days off.

Figure 5 considers personal care. Remarkably, there is a very regular pattern of providing personal care from caregivers without any paid work during the day. Four peaks are observable for this group, which are at 9:00 a.m., 1:00 p.m., 6:00 p.m., and a small peak at 11:00 p.m.; the first and third peak (9:00 a.m., 6:00 p.m.) are of about equal size. At these moments, the probability of personal care is about 30 percentage points higher (relative to 0:00 a.m. - 0:15 a.m.). In contrast, for the employed caregivers on a day off, there are no peaks observable between 8:00 a.m. and 10:00 p.m. It implies that for these caregivers, we

cannot observe any specific rhythm of personal care during the day. On the days of paid work, there is a relatively small peak at 9:00 a.m. and larger peak at 7:00 p.m.

Overall, the Figures 3 and 4 imply that for household activities and for organization, there are no specific differences in patterns of informal care between caregivers without paid work and the counterfactual observations. Hence, there seem to be no additional opportunity costs of timing informal care. Both types of informal care are shiftable throughout the day for the employed caregivers. On the other hand, to a larger extent, personal care seems to be unshiftable throughout the day (Figure 5). For this activity the pattern throughout the day is substantially different between caregivers without paid work and the counterfactual observations. It implies that there are time-bound opportunity costs involved in the timing of personal care. In terms of equation (2), $C T$ influences $H$ when it pertains to personal care.

\section{Conclusion and discussion}

We extend the literature on informal caregiving by considering differences between specific activities of informal care as well as differences between fluctuations of informal care across the day. Our conclusion is threefold.

First, we observed whether informal caregivers were able to reduce opportunity costs by joint production, combining informal care with other activities. Informal care involves a substantial degree of simultaneity with household activities, while it seems to be impossible to 
combine it with paid work. This latter result seems to underscore the importance of the counterfactual that we applied; the activities on the days employed caregivers had no obligations of paid work. We identified a novel source of opportunity costs - time bound opportunity costs - that pertain to the possibility to shift tasks of informal care. Some tasks are relatively unshiftable, while other tasks can be performed at other moments of the day. In particular, household and organization seem to be shiftable for employed caregivers, while personal care seems to be unshiftable. It implies that there is an additional source of opportunity costs for providing personal care.

Second, time-bound opportunities costs may disturb the validity of care need as instrumental variable, when estimating the causal effect of (the provision of) informal care on labour supply. As long as informal care only involves household and organizational activities, the care recipient's need seems to be a valid instrument, as the error term of the labour supply equation is unrelated to time-bound opportunity costs. However, time-bound opportunities costs of personal care are relatively high for employed caregivers. Consequently, care need cannot be an exogenous instrument for personal care, since it is correlated with the time bound costs that are contained by the error term of the labour supply equation. This finding underscores the necessity to distinguish between the different types of informal care.

Third, for developing health policy, we argue that a small, in terms of level, routine that should repeatedly been done every day (viz. is unshiftable) could involve a similar amount of subjective burden experienced compared with a larger, again in terms of level, informal care activity. This could be taken into account when care recipients are granted access to publicly funded welfare services in the form of professional care, as e.g. in Scotland where free personal care was introduced in 2002 (Comas-Herrera, 2010). Moreover, for informal caregivers with a paid-job provision of personal care might be much more troublesome, because it seems less easily performed simultaneously and because to a certain extent it is unshiftable. This should be acknowledged in providing care recipients access to professional care and in developing respite care programs. One could also think of experimenting with services intended to support carers to combine paid work and caregiving, flexible working arrangements, working from home, and use of new technologies such as communication systems, assistive devices and telecare.

A limitation of this study is that it is based on a relatively small cross-sectional sample of informal caregivers who were approached via support centres. In addition, the comparison between both groups (carers with and without paid work) may be influenced by different confounders. Despite these limitations, we believe that we have pointed out an important 
omission in the literature of informal caregiving. The additional time-bound opportunity costs may have implications for many aspects of caregivers' lives including social and leisure activities and family life. This might also hold up for paid work. Similar informal caregivers may face quite different opportunity costs (with paid jobs for the same number of hours and days per week) because they are associated with daily time-bound care tasks (and periodic tasks such as accompanying the care recipient to hospital appointments). It partly depends on the terms, conditions and circumstances of employment. Future research on the impact of informal care on labour supply by using instrumental variables should consider to include information on unshiftable routines which are related to necessity to time, because alternatively their instruments are likely to be invalid. 


\section{Literature}

Andrén, S., Elmståhl, S. (2005). Family caregivers' subjective experiences of satisfaction in dementia care: aspects of burden, subjective health and sense of coherence. Scandinavian Journal of Caring Sciences, 19, 157-168.

Bolin K., Lindgren B., Lundborg P. (2008). Your next of kin or your own career? Caring and working among the 50+ of Europe. Journal of Health Economics, 27, 718-738.

Carmichael, F., Charles, S. (2003). The opportunity costs of informal care: does gender matter? Journal of Health Economics, 22, 781-803.

Comas-Herrera, A., Wittenberg, R. Pickard, L. (2010). The Long Road to Universalism? Recent Developments in the Financing of Long-term Care in England. Social Policy \& Administration, 44, 375-391.

Davis, K.L., Marin, D.B., Kane, R., Patrick, D., Peskind, E.R., Raskind, M.A., \& Puder, K.L. (1997). The Caregiver Activity Survey (CAS): development and validation of a new measure for caregivers of persons with Alzheimer's disease. International Journal of Geriatric Psychiatry, 12, 978-88.

Dunn, N.J., Strain, L.A. (2001). Caregivers at risk? Changes in leisure participation. Journal of Leisure Research, 33, 32-55.

Ettner, S.L. (1996). The opportunity costs of elder care. Journal of Human Resources, 31, 189-205.

Heitmueller, A. (2007). The chicken or the egg? Endogeneity in labour market participation of informal carers in England. Journal of Health Economics, 26, 536-559.

Heitmueller, A., Inglis, K. (2007). The earnings of informal carers: Wage differentials and opportunity costs. Journal of Health Economics, 26: 821-841. 
Hirst, M. (2005). Carer distress: A prospective, population-based study. Social Science and Medicine, 61, 697-708.

Hughes S.L., Giobbie-Hurder A., Weaver F.M., Kubal J.D., Henderson W. (1999).

Relationship between caregiver burden and health-related quality of life. Gerontologist, 39, 534-45.

Hurley, J. (2000). An overview of the normative economics of the health sector. In A. Culyer \& J.P. Newhouse (Eds.), Handbook of Health Economics (pp.56-118), Amsterdam: Elsevier.

Jacobi, C., Van den Berg, B., Boshuizen, H., Rupp, I., Dinant, H., Van den Bos, T. (2003). Dimension-specific burden of caregiving among partners of rheumatoid arthritis patients. Rheumatology, 42, 1-8.

Juster, F.T., Stafford F.P. (1991). The allocation of time: empirical findings, behavioral models, and problems of measurement. Journal of Economic Literature, XXIX, 471-522.

Kramer, B.J. (1997). Gain in the caregiving experience: Where are we? What next? Gerontologist, 37, 218-232.

McDaid, D. (2001). Estimating the costs of informal care for people with Alzheimers's disease: methodological and practical challenges. International Journal of Geriatric Psychiatry, 16, 400-405.

Mohide, E.A., Torrance, G.W., Streiner, D.L., Pringle, D.M., Gilbert, R. (1988). Measuring the wellbeing of family caregivers using the time trade-off technique. Journal of Clinical Epidemiology, 41, 475-482.

Norton, E.C. (2000). Long-term care. In A. Culyer \& J.P. Newhouse (Eds.), Handbook of Health Economics (pp. 955-994), Amsterdam: Elsevier.

Pearlin, L.I., Mullan, J.T., Semple, S.J., Skaff, M.M. (1990). Caregiving and the stress process: an overview of concepts and their measures. Gerontologist, 30, 583-594. 
Posnett, J., Jan, S. (1996). Indirect cost in economic evaluation: the opportunity cost of unpaid inputs. Health Economics, 5, 13-23.

Riewpaiboon, A., Riewpaiboon, W., Ponsoongnern, K., Van den Berg, B. (2009). Economic valuation of informal care in Asia: A case study of care for disabled stroke survivors in Thailand. Social Science and Medicine, 69, 648-653.

Savage, S., Bailey, S. (2004). The impact of caring on caregivers' mental health: a review of the literature. Australian Health Review, 27, 111-117.

Schulz, R., Beach, S.R. (1999). Caregiving as a risk factor for mortality: the Caregiver Health Effects Study. Journal of the American Medical Association, 282, 2215-2219.

Smith, K., Wright, K. (1994). Informal care and economic appraisal: a discussion of possible methodological approaches. Health Economics, 3, 137-148.

Van den Berg, B., Bleichrodt, H., Eeckhoudt, L. (2005). The economic value of informal care: A study of informal caregivers' and patients' willingness to pay and willingness to accept for informal care. Health Economics, 14, 363-376.

Van den Berg, B., Brouwer, W.B.F., Koopmanschap, M.A. (2004). Economic valuation of informal care: An overview of methods and applications. European Journal of Health Economics, 5, 36-45.

Van den Berg, B., Brouwer, W., Koopmanschap, M., Van Exel, J., Van den Bos, G.A.M., Rutten, F. (2006). Economic valuation of informal care: Lessons from the application of the opportunity cost and proxy good methods. Social Science and Medicine, 62, 835-845.

Van den Berg, B., Hassink, W.H.J. (2008). Cash benefits in long-term home care. Health Policy, 88, 209-221.

Van den Berg, B., Spauwen, P. (2006). Measurement of informal care: An empirical study into the valid measurement of time spent on informal caregiving, Health Economics, 15, 447460. 
Van Houtven, C.H., Norton, E.C. (2004). Informal care and health care use of older adults. Journal of Health Economics, 23, 1159-1180.

Wilson, Ira B., Cleary, Paul D. (1995). Linking clinical variables with health-related quality of life: A conceptual model of patient outcomes. Journal of the American Medical Association, 273, 59-65.

Wimo, A., Von Strauss, E., Nordberg, G., Sassi, F., Johansson, L. (2002). Time spent on informal and formal care giving for persons with dementia in Sweden. Health Policy, 61, 255268.

Wooldridge, J.M. (2002), Econometric Analysis of Cross Section and Panel Data, MIT Press: London.

Yamazaki, S., Sokejima, S., Mizoue, T., Eboshida, A., Fukuhara, S. (2005). Health-related quality of life of mothers of children with leukaemia in Japan. Quality of Life Research, 14, 1079-1085.

Zapart, S., Kenny, P., Hall, J., Servis, B., Wiley, S. (2007). Home-based palliative care in Sydney Australia: The carer's perspective on the provision of informal care. Health and Social Care in the Community, 15, 97-107. 
Table 1 - Descriptive statistics of caregivers ${ }^{\text {a) }}$

\begin{tabular}{|c|c|c|c|c|}
\hline & $\begin{array}{c}\text { All } \\
\text { caregivers }\end{array}$ & $\begin{array}{l}\text { Employed } \\
\text { caregivers }\end{array}$ & $\begin{array}{c}\text { Caregivers } \\
\text { without paid job }\end{array}$ & $\begin{array}{c}\text { Two sample } \\
\text { t-test on } \\
\text { equality } \\
\text { (p-value) }\end{array}$ \\
\hline Age caregiver & $\begin{array}{c}56.6 \\
(12.2)\end{array}$ & $\begin{array}{l}49.5 \\
(7.8)\end{array}$ & $\begin{array}{c}60.4 \\
(12.4)\end{array}$ & 0.000 \\
\hline Male & $\begin{array}{c}0.29 \\
(0.45)\end{array}$ & $\begin{array}{c}0.29 \\
(0.46)\end{array}$ & $\begin{array}{c}0.29 \\
(0.45)\end{array}$ & 0.938 \\
\hline $\begin{array}{l}\text { Number of years } \\
\text { of education }\end{array}$ & $\begin{array}{l}13.7 \\
(2.7)\end{array}$ & $\begin{array}{l}14.4 \\
(2.4)\end{array}$ & $\begin{array}{l}13.4 \\
(2.8)\end{array}$ & 0.021 \\
\hline Married & $\begin{array}{c}0.84 \\
(0.37)\end{array}$ & $\begin{array}{c}0.91 \\
(0.29)\end{array}$ & $\begin{array}{c}0.80 \\
(0.40)\end{array}$ & 0.062 \\
\hline $\begin{array}{l}\text { Household income } \\
\text { (in euros) }\end{array}$ & $\begin{array}{l}1747 \\
(741)\end{array}$ & $\begin{array}{l}1990 \\
(684)\end{array}$ & $\begin{array}{l}1618 \\
(741)\end{array}$ & 0.000 \\
\hline $\begin{array}{l}\text { Lives together } \\
\text { with care recipient }\end{array}$ & $\begin{array}{c}0.66 \\
(0.48)\end{array}$ & $\begin{array}{c}0.53 \\
(0.50)\end{array}$ & $\begin{array}{c}0.72 \\
(0.45)\end{array}$ & 0.008 \\
\hline Age care recipient & $\begin{array}{c}59.7 \\
(24.7)\end{array}$ & $\begin{array}{c}54.3 \\
(25.9)\end{array}$ & $\begin{array}{c}62.6 \\
(23.6)\end{array}$ & 0.133 \\
\hline $\begin{array}{l}\text { Care recipient } \\
\text { male }\end{array}$ & $\begin{array}{c}0.52 \\
(0.50)\end{array}$ & $\begin{array}{c}0.45 \\
(0.50)\end{array}$ & $\begin{array}{c}0.56 \\
(0.50)\end{array}$ & 0.027 \\
\hline Persons & 199 & 69 & 130 & \\
\hline
\end{tabular}

a) Standard errors in parentheses. 
Table 2 - Descriptive statistics: activities ${ }^{\text {a) }}$

\begin{tabular}{|c|c|c|c|c|}
\hline & $\begin{array}{c}\text { All } \\
\text { caregivers }\end{array}$ & $\begin{array}{c}\text { Employed } \\
\text { caregivers; } \\
\text { day with paid } \\
\text { work } \\
\text { obligations }\end{array}$ & $\begin{array}{l}\text { Employed } \\
\text { caregivers; } \\
\text { day without } \\
\text { paid work } \\
\text { obligations }\end{array}$ & $\begin{array}{c}\text { Caregivers } \\
\text { without } \\
\text { paid job }\end{array}$ \\
\hline $\begin{array}{l}\text { Informal care, } \\
\text { household }\end{array}$ & $\begin{array}{c}10.0 \\
(30.0)\end{array}$ & $\begin{array}{c}5.8 \\
(23.3)\end{array}$ & $\begin{array}{c}10.0 \\
(30.0)\end{array}$ & $\begin{array}{c}11.3 \\
(31.7)\end{array}$ \\
\hline $\begin{array}{l}\text { Informal care, } \\
\text { organization }\end{array}$ & $\begin{array}{c}21.6 \\
(41.2)\end{array}$ & $\begin{array}{c}11.7 \\
(32.2)\end{array}$ & $\begin{array}{c}16.5 \\
(37.1)\end{array}$ & $\begin{array}{c}25.8 \\
(43.8)\end{array}$ \\
\hline $\begin{array}{l}\text { Informal care, } \\
\text { personal care }\end{array}$ & $\begin{array}{c}10.7 \\
(30.9)\end{array}$ & $\begin{array}{c}5.3 \\
(22.4)\end{array}$ & $\begin{array}{c}9.5 \\
(29.4)\end{array}$ & $\begin{array}{c}12.6 \\
(33.2)\end{array}$ \\
\hline Informal care & $\begin{array}{c}34.1 \\
(47.4)\end{array}$ & $\begin{array}{c}20.3 \\
(40.2)\end{array}$ & $\begin{array}{c}28.6 \\
(45.2)\end{array}$ & $\begin{array}{c}39.4 \\
(48.9)\end{array}$ \\
\hline Paid work & $\begin{array}{c}5.0 \\
(21.9)\end{array}$ & $\begin{array}{c}25.8 \\
(43.7)\end{array}$ & $\begin{array}{c}0.0 \\
(0.0)\end{array}$ & $\begin{array}{c}0.0 \\
(0.0)\end{array}$ \\
\hline $\begin{array}{l}\text { Biological } \\
\text { activities }\end{array}$ & $\begin{array}{c}39.4 \\
(48.9)\end{array}$ & $\begin{array}{c}37.3 \\
(48.4)\end{array}$ & $\begin{array}{c}40.1 \\
(49.0)\end{array}$ & $\begin{array}{c}39.9 \\
(49.0)\end{array}$ \\
\hline Leisure & $\begin{array}{c}22.0 \\
(41.4)\end{array}$ & $\begin{array}{c}17.8 \\
(38.3)\end{array}$ & $\begin{array}{c}24.0 \\
(42.7)\end{array}$ & $\begin{array}{c}22.8 \\
(42.0)\end{array}$ \\
\hline $\begin{array}{l}\text { Household } \\
\text { activities }\end{array}$ & $\begin{array}{c}19.6 \\
(39.7)\end{array}$ & $\begin{array}{c}12.4 \\
(33.0)\end{array}$ & $\begin{array}{c}23.0 \\
(42.1)\end{array}$ & $\begin{array}{c}21.0 \\
(40.7)\end{array}$ \\
\hline Total & $\begin{array}{l}120.1 \\
(52.5)\end{array}$ & $\begin{array}{l}113.6 \\
(48.5)\end{array}$ & $\begin{array}{l}115.7 \\
(48.7)\end{array}$ & $\begin{array}{l}123.1 \\
(54.2)\end{array}$ \\
\hline Time periods & 38,233 & 7,478 & 5,750 & 25,005 \\
\hline Days & 398 & 78 & 60 & 260 \\
\hline Persons & 199 & \multicolumn{2}{|c|}{69} & 130 \\
\hline
\end{tabular}

a) Standard errors in parentheses. Total is the sum of informal care, paid work, biological activities, leisure, and household activities. 
Table 3 - Simultaneous activities between informal care and correlations ${ }^{\text {a) }}$

\begin{tabular}{|c|c|c|c|c|}
\hline & $\begin{array}{c}\text { All } \\
\text { caregivers }\end{array}$ & $\begin{array}{c}\text { Employed } \\
\text { caregivers; } \\
\text { day with } \\
\text { paid work } \\
\text { obligations }\end{array}$ & $\begin{array}{c}\text { Employed } \\
\text { caregivers; } \\
\text { day without } \\
\text { paid work } \\
\text { obligations }\end{array}$ & $\begin{array}{c}\text { Caregivers } \\
\text { without paid } \\
\text { job }\end{array}$ \\
\hline Paid work & $\begin{array}{c}0.5 \% \\
(6.7) \\
{[-0.12]}\end{array}$ & $\begin{array}{c}2.3 \% \\
(15.0) \\
{[-0.17]}\end{array}$ & $\begin{array}{l}0.0 \% \\
(0.0)\end{array}$ & $\begin{array}{l}0.0 \% \\
(0.0)\end{array}$ \\
\hline Biological activities & $\begin{array}{c}4.7 \% \\
(21.2) \\
{[-0.38]}\end{array}$ & $\begin{array}{c}2.3 \% \\
(14.9) \\
{[-0.27]}\end{array}$ & $\begin{array}{c}2.6 \% \\
(15.9) \\
{[-0.40]}\end{array}$ & $\begin{array}{c}5.9 \% \\
(23.6) \\
{[-0.41]}\end{array}$ \\
\hline Leisure & $\begin{array}{c}6.4 \% \\
(24.4) \\
{[-0.06]} \\
\end{array}$ & $\begin{array}{l}4.5 \% \\
(20.6) \\
{[0.05]} \\
\end{array}$ & $\begin{array}{c}4.5 \% \\
(20.7) \\
{[-0.12]} \\
\end{array}$ & $\begin{array}{c}7.4 \% \\
(26.1) \\
{[-0.08]} \\
\end{array}$ \\
\hline Household activities & $\begin{array}{l}10.6 \% \\
(30.8) \\
{[0.21]} \\
\end{array}$ & $\begin{array}{l}5.6 \% \\
(22.9) \\
{[0.23]} \\
\end{array}$ & $\begin{array}{l}8.7 \% \\
(28.2) \\
{[0.11]} \\
\end{array}$ & $\begin{array}{l}12.6 \% \\
(33.1) \\
{[0.22]} \\
\end{array}$ \\
\hline Total & $\begin{array}{l}20.7 \% \\
(40.5)\end{array}$ & $\begin{array}{l}12.8 \% \\
(33.4)\end{array}$ & $\begin{array}{l}14.6 \% \\
(35.3)\end{array}$ & $\begin{array}{l}24.5 \% \\
(43.0)\end{array}$ \\
\hline Time periods & 38,233 & 7,478 & 5,750 & 25,005 \\
\hline
\end{tabular}

a) Simultaneity is measured as daily percentages; standard error of means in parentheses. Correlation between the dummies of informal care and each activity is given in square brackets. All of the correlation coefficients are statistically different from zero at the 1-percent level. 
Figure 1- Activities

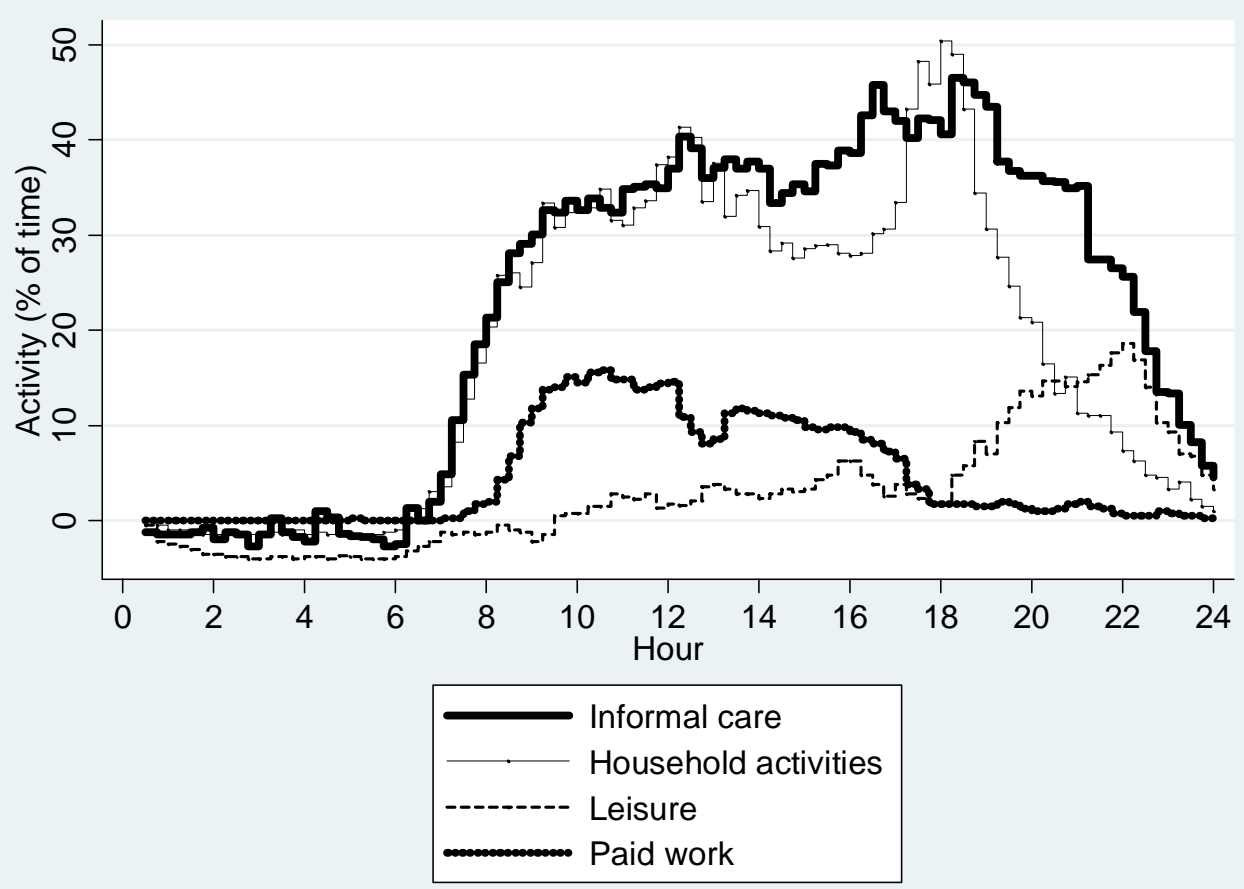


Figure 2 - Simultaneity of informal care with other activities

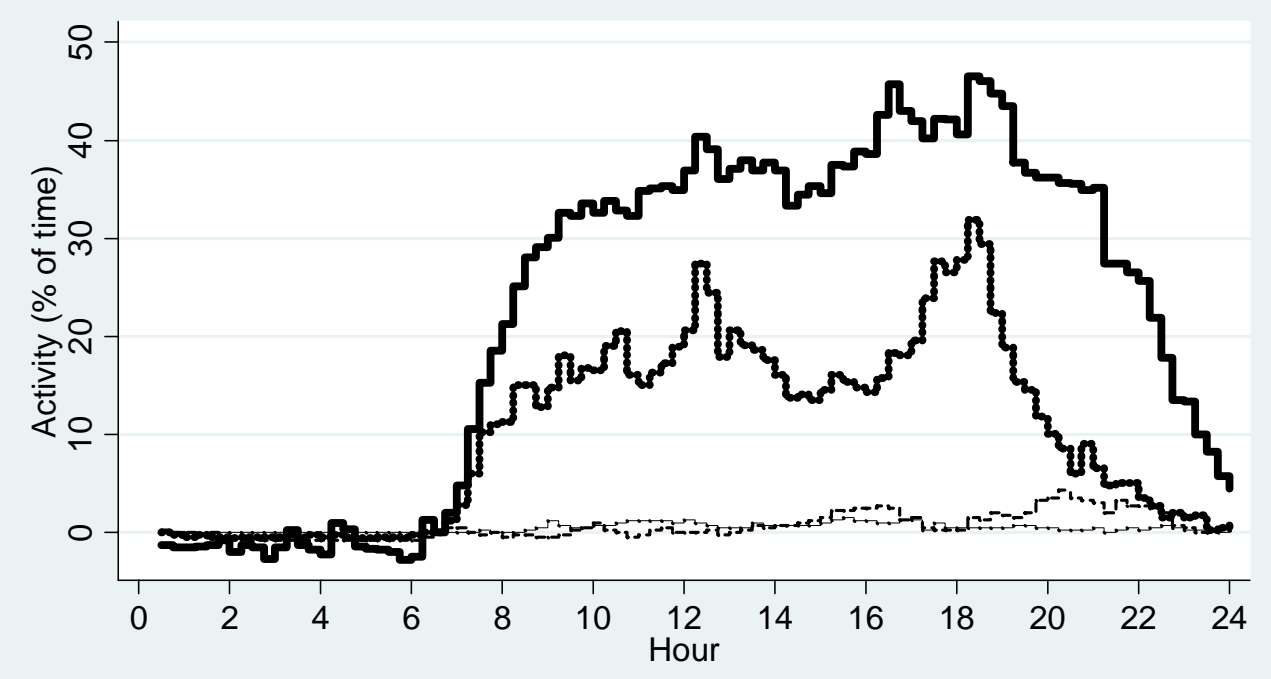

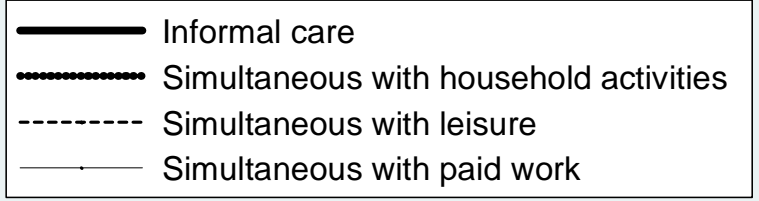


Figure 3: Informal care: household activities

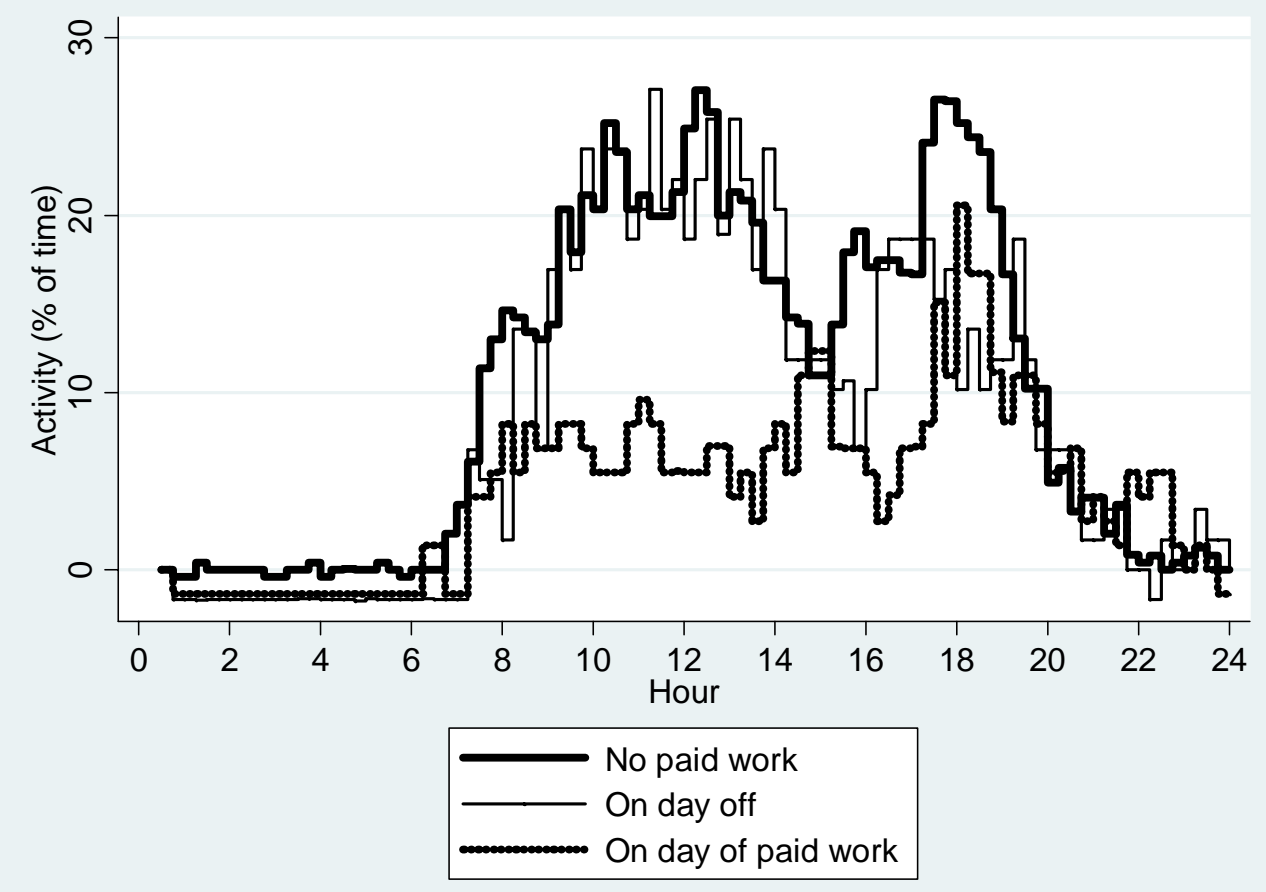


Figure 4: Informal care: Organisation

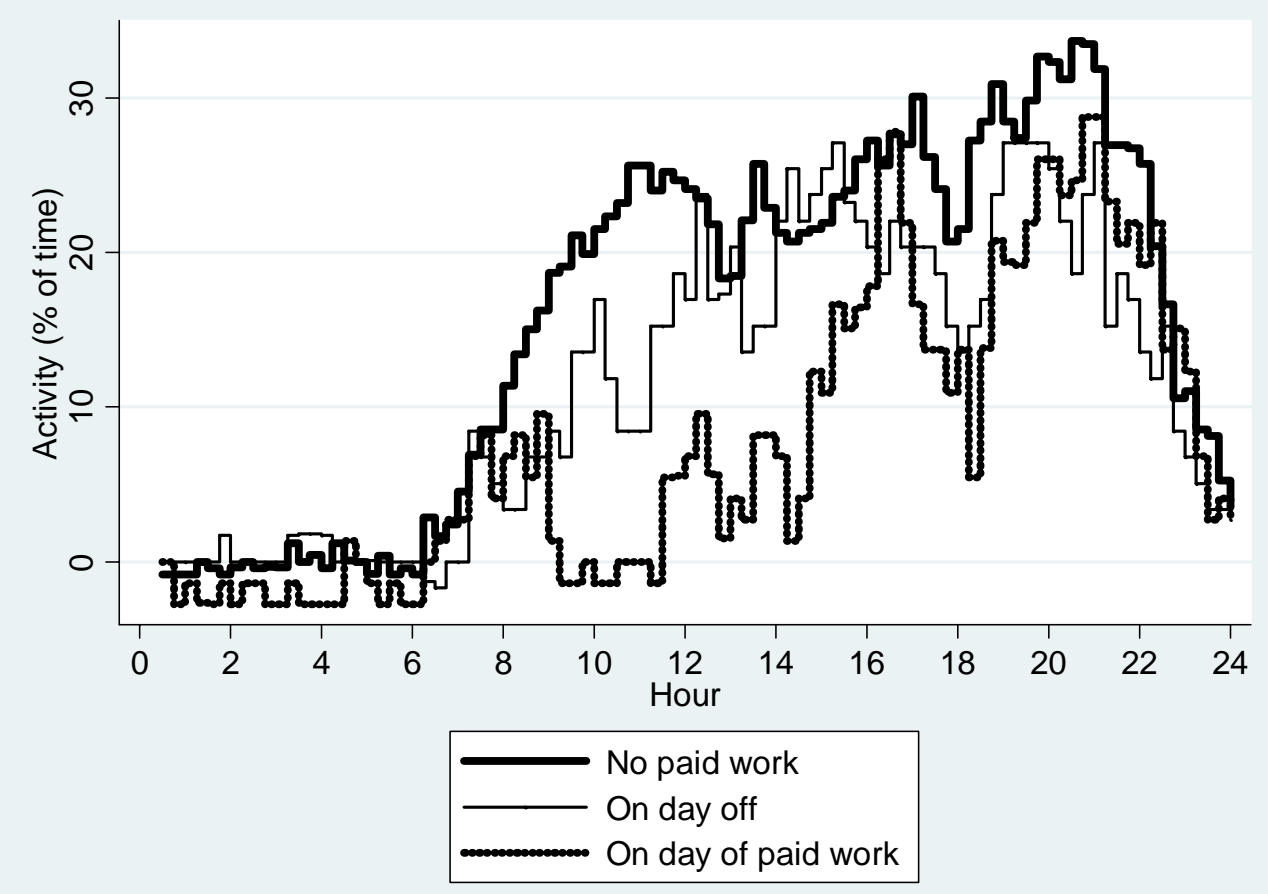


Figure 5: Informal care: Personal care

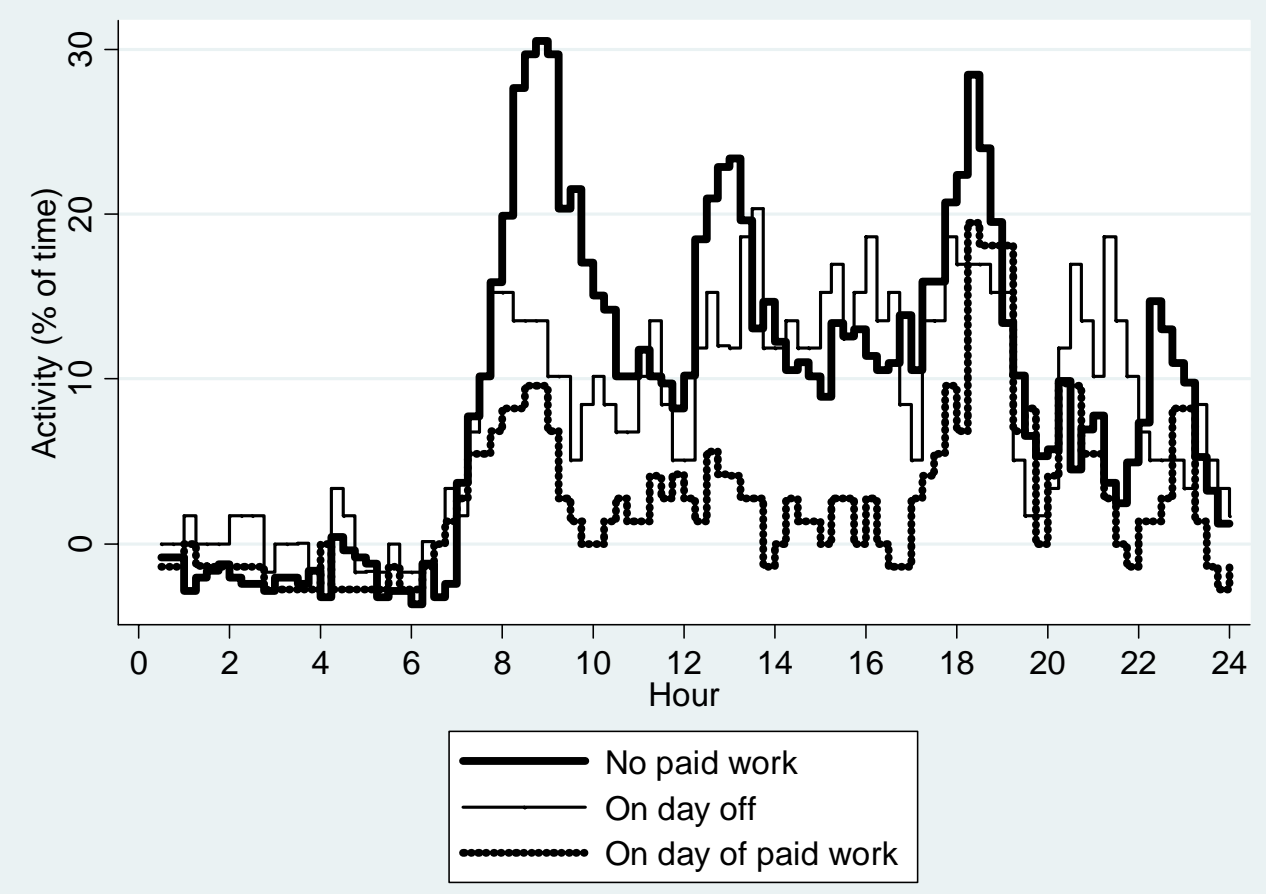

